\title{
Determinants of uterine rupture in Dessie Referral Hospital, North East Ethiopia, 2016: case control design
}

\author{
Amare Workie $^{1}$, Yemmiamrew Getachew ${ }^{2}$, Kibir Temesgen ${ }^{1}$, Prem Kumar ${ }^{2 *}$ \\ ${ }^{1}$ Department of Midwifery, ${ }^{2}$ Department of Comprehensive Nursing, College of Medicine and Health Sciences
} (CMHS), Wollo University, Ethiopia

Received: 03 March 2018

Accepted: 28 March 2018

*Correspondence:

Dr. Prem Kumar,

E-mail: greenwater3020@gmail.com

Copyright: (c) the author(s), publisher and licensee Medip Academy. This is an open-access article distributed under the terms of the Creative Commons Attribution Non-Commercial License, which permits unrestricted non-commercial use, distribution, and reproduction in any medium, provided the original work is properly cited.

\begin{abstract}
Background: Uterine rupture remains a major obstetric problem particularly in less developed countries. The aim of this study was to identify determinants of uterine rupture among mothers getting delivery services in Dessie Referral Hospital from January 2016 to June 2016, North East Ethiopia.

Methods: A prospective unmatched case control study was conducted recruiting 42 mothers with uterine rupture as case group and 168 for control group. Pretested, structured questionnaire was used to collect data.

Results: Descriptive statistics and Logistic regression models were utilized considering 95\% confidence interval and p-value of 0.05 to determine the presence and strength of association between dependent and independent variables. Majority (94.2\%) of cases came from rural areas, $76.2 \%$ had obstructed labor and 55\% had prolonged labor. Of $85.7 \%$ of cases have reported number of pregnancies $\geq 5$. Mothers who encountered obstructed labor and previous Caesarean section scar were at higher risk of uterine rupture $(\mathrm{AOR}=22.2,95 \% \mathrm{CI}=2.8-4.1$ and $\mathrm{AOR}=13.6,95 \%$ $\mathrm{CI}=2.16-17.84$ respectively). Mothers living in urban area, having Antenatal Care follow-up, shorter labor stay and primi-parity were found to have lower risk of uterine rupture.

Conclusions: This study revealed that living in rural areas, absence of Antenatal Care follow-up, prolonged labor, obstructed labor, grand multiparity and previous Caesarean section scar were determinants of uterine rupture. Viable strategies have to be designed and implemented to tackle these determinants of uterine rupture.
\end{abstract}

Keywords: Determinants, Ethiopia, Uterine rupture

\section{INTRODUCTION}

Every year about 287,000 women die due to causes related to pregnancy and childbirth. Maternal mortality in developing countries is 50 times higher compared to developed countries. ${ }^{1,2}$ Uterine rupture occurs when there is partial or full thickness disruption in uterine wall. It can occur during pregnancy or labor either spontaneously or in women with surgical scar from previous surgery. ${ }^{3}$

Uterine rupture is a major obstetric problem associated with higher maternal and fetal mortality and morbidity particularly in the least developed regions..$^{4-7}$ It is associated with significant uterine bleeding and fetal distress necessitating prompt delivery, major surgery or uterine rent. ${ }^{8-11}$ It is an obstetric catastrophe contributing for as many as $9.3 \%$ of maternal deaths. ${ }^{12}$

The incidence of ruptured uterus varies in different parts of the world. Systematic review of literature showed that median incidence of uterine rupture was 5.3 per 10000 births with much higher incidence in developing countries. $^{11,13,14}$

In developed countries the incidence is less than 1 per 1000 deliveries. ${ }^{15,16}$ Different studies in Ethiopia showed 
that the incidence of uterine rupture ranges from $0.3 \%$ to $2.4 \% .^{7,9,17-19}$ Several factors are known to increase the risk of uterine rupture. In industrialized countries, uterine rupture occurs mostly due to previous uterine scar whereas in developing nations it is commonly associated with obstructed labor, injudicious obstetric interventions, lack of antenatal care (ANC), grand multiparity, poor socio-economic status, illiteracy, contracted pelvis, congenital anomaly and poor access to emergency obstetric care. ${ }^{18,20}$ Spontaneous rupture of an intact uterus might be due to injudicious use of oxytocin, commonly used uterotonic agent, cephalopelvic disproportion (CPD), mal-presentation, multi-parity, instrumental delivery and obstetrical manipulations. ${ }^{21,22}$

Though promising progress has been achieved in post millennium years, there is still a lot to be done to address multiple factors which determine maternal mortality. Feto-maternal and clinical factors contributing for uterine rupture are among the major etiology of maternal mortality and morbidity.

The incidence of uterine rupture is relatively high (1.6\%) in Dessie Referral Hospital (DRH), north east Ethiopia. But no studies conducted to investigate determinants of uterine rupture in this part of the country. Thus, this study was designed and implemented to identify determinants of uterine rupture among mothers getting delivery services in Dessie referral hospital.

The result of this study may help policy makers, stakeholders and health professionals to design appropriate interventions to reduce the incidence of uterine rupture and thereby improve feto-maternal outcomes.

\section{METHODS}

Unmatched prospective case control study design was employed after getting ethical approval from institutional ethical review committee of college of medicine and health sciences, Wollo University. The study was carried out in delivery Unit of Dessie referral hospital, north east Ethiopia from January 2016 to June 2016.

Double population proportion formula was used to calculate sample size using EpiInfo 7. Exposure among cases was taken to be $14 \%$ (Previous study in Black Lion Hospital Addis Ababa, Ethiopia). Power of $80 \%$, 95\% confidence interval and 1:4 case and control ratios were taken in determining the sample size. A total of 210 mothers (42 cases and 168 controls) were included in this study. Cases were selected incidentally and controls were selected randomly from mothers who gave birth during the study period.

\section{Case definition}

Cases were defined as, all women in DRH identified as having a uterine rupture with complete or partial separation of the wall of the uterus, with or without expulsion of fetus endangering the life of the mother or fetus. ${ }^{8}$ The diagnosis was made by senior duty staff.

\section{Control definition}

Controls were defined as woman who gave birth with any mode of delivery but had not suffered from a uterine rupture.

\section{Data collection procedures}

Structured pre-tested face to face interviewer administered questionnaire was developed reviewing related literature. Medical Chart of all women was reviewed using structured checklist. The study tool had three sections. The first section was prepared to collect data related to socio-demographic characteristics of the women. The second section comprises obstetric factors (Parity, ANC visit, Duration of labor, previous $\mathrm{C} / \mathrm{s}$ scar and multiple pregnancies) and clinical factors (duration of labor, use of uterotenic drugs, instrumental delivery, uterine scar, mal-presentation/position and obstructed labor) were addressed in the third section. In this study big baby was defined as birth weight of more than $4 \mathrm{~kg}$. Prolonged labor was also defined as labor that lasts $>20$ hours in first stage of labor, and 1 hour and 2 hours during second stage in multi-para and primi-para women respectively.

The other main variable in this study, obstructed labor was defined as labor with the features of obstruction like bandle's ring, excessive fetal head molding or caput, malpresentations, vulvar edema, maternal exhaustion and dehydration as identified by senior duty staff member.

Data collectors completed the data collection tool for the case before discharge of the women. Representative samples of controls were selected randomly on the day of giving birth and interviewed.

\section{Data analysis}

Data was cleaned and cross checked before analysis. Then, coded and entered to EPI Info version 7, exported to SPSS version 20 for further analysis. Descriptive (frequency table, mean and graphs) and analytical statistics were used for data presentation. Comparison of risk factors for uterine rupture for cases and controls was completed during similar time frame.

Bivariate logistic regression was employed to identify factors associated with uterine rupture by entering individual variables separately. Those variables having $\mathrm{p}$ value of $<0.2$ on bivariate analysis were taken to multiple logistic regression to control possible effect of confounders.

Finally, those variables which have p-value of less than 0.05 with $95 \%$ confidence interval were declared as 
having statistically significant association with uterine rupture.

\section{RESULTS}

\section{Socio-demographic characteristics of women}

A total of 210 women were enrolled in this study. The mean age of case was 27 years (SD of \pm 6.4 ). Majority $(92.9 \%)$ of women were in the age between 21 and 34 years. Mean age of women in control group was 25 years (SD of \pm 5.2 ).

More than ninety seven percent $(97.6 \%)$ cases and $99.4 \%$ of controls were married. Regarding educational status of women, majority $(45.2 \%)$ of cases and $36.3 \%$ of controls had attended primary education. Forty $(94.2 \%)$ of cases and eighty five $(50.2 \%)$ of controls were living in rural areas.

Table 1: Socio-demographic characteristics of women visited Dessie Referral Hospital delivery unit from January 2016 to June $2016(n=210)$.

\begin{tabular}{|c|c|c|c|}
\hline \multicolumn{2}{|l|}{ Variable } & $\begin{array}{l}\text { Case } \\
\mathrm{N}=42\end{array}$ & $\begin{array}{l}\text { Control } \\
\mathrm{N}=168\end{array}$ \\
\hline \multirow{3}{*}{ Age } & $<20$ & $2(4.8 \%)$ & $4(2.4 \%)$ \\
\hline & $21-34$ & $39(92.9 \%)$ & $158(94.0 \%)$ \\
\hline & $>35$ & $1(2.4 \%)$ & $6(3.6 \%)$ \\
\hline \multirow{2}{*}{$\begin{array}{l}\text { Marital } \\
\text { Status }\end{array}$} & Single & $1(2.4 \%)$ & $1(0.6 \%)$ \\
\hline & Married & $41(97.6 \%)$ & $167(99.4 \%)$ \\
\hline \multirow{3}{*}{ Religion } & Orthodox & $16(38.1 \%)$ & $109(64.9 \%)$ \\
\hline & Muslim & $21(50.0 \%)$ & $54(32.1 \%)$ \\
\hline & Protestant & $5(11.9 \%)$ & $5(3.0 \%)$ \\
\hline \multirow{2}{*}{ Residence } & Urban & $2(4.8 \%)$ & $83(49.4 \%)$ \\
\hline & Rural & $40(94.2 \%)$ & $85(50.2 \%)$ \\
\hline \multirow{3}{*}{ Ethnicity } & Amhara & $39(95.2 \%)$ & $161(95.83 \%)$ \\
\hline & Tigray & $3(4.8 \%)$ & $6(3.57 \%)$ \\
\hline & Oromo & - & $1(0.60 \%)$ \\
\hline \multirow{5}{*}{$\begin{array}{l}\text { Educational } \\
\text { Status }\end{array}$} & $\begin{array}{l}\text { Unableto } \\
\text { read and } \\
\text { write }\end{array}$ & $5(11.9 \%)$ & $26(15.5 \%)$ \\
\hline & $\begin{array}{l}\text { Read and } \\
\text { write }\end{array}$ & $6(14.3 \%)$ & $62(36.9 \%)$ \\
\hline & $\begin{array}{l}\text { Primary } \\
\text { school }\end{array}$ & $19(45.2 \%)$ & $61(36.3 \%)$ \\
\hline & $\begin{array}{l}\text { Secondary } \\
\text { School }\end{array}$ & $9(21.4 \%)$ & $11(6.5 \%)$ \\
\hline & $\begin{array}{l}\text { Higher } \\
\text { Education }\end{array}$ & $3(7.1 \%)$ & $8(4.8 \%)$ \\
\hline
\end{tabular}

\section{Obstetric characteristics}

Concerning type of pregnancy, all of cases and $97.6 \%$ of women in control group had single pregnancy. Regarding gestational age, $32(76.2 \%)$ of cases and $150(89.3 \%)$ of controls gave birth at full term (37-40 weeks). Most
(92.9\%) of cases had no ANC follow up while $89.3 \%$ of women in the control group had it during most recent pregnancy.

Concerning number of pregnancy, most $(86.4 \%)$ of cases were grand multipara while $48.8 \%$ of women in the control group had 2-5 pregnancies.

More than Fifty six percent of cases and $16.3 \%$ of controls had history of uterine scar from either previous caesarian section or other form of uterine surgery.

\section{Clinical Factors}

From the total respondents $32(76.2 \%)$ of cases and 20 $(11.9 \%)$ of women in the control group had obstructed labor. In Twenty three $(54.7 \%)$ of cases and $9(5.3 \%)$ of women in the control group labor lasted more than 25 hours. In $68.2 \%$ of cases and $13.7 \%$ of women in the control group had malpresentation during labor.

Concerning course of uterine contraction, in about 28 $(68.2 \%)$ of cases and $86.3 \%$ of women in the control group labor was spontaneous (without induction and augmentation).

Table 2: Labor and delivery characteristics of women visited Dessie Referral Hospital delivery unit from January 2016 to June $2016(n=210)$.

\begin{tabular}{|c|c|c|c|}
\hline \multicolumn{2}{|l|}{ Variable } & $\begin{array}{l}\text { Cases } \\
\mathrm{N}=42\end{array}$ & $\begin{array}{l}\text { Controls } \\
\mathrm{N}=168\end{array}$ \\
\hline \multirow{2}{*}{$\begin{array}{l}\text { Obstructed } \\
\text { labor }\end{array}$} & Yes & $32(76.2 \%)$ & $120(11.9 \%)$ \\
\hline & No & $10(23.8 \%)$ & $148(88.1 \%)$ \\
\hline \multirow{4}{*}{$\begin{array}{l}\text { Duration of } \\
\text { labor }\end{array}$} & $<8 \mathrm{hrs}$ & $2(4.8 \%)$ & $41(24.4 \%)$ \\
\hline & 9-14hrs & $4(9.5 \%)$ & $90(53.6 \%)$ \\
\hline & $15-24$ & $13(30.9 \%)$ & $28(16.7 \%)$ \\
\hline & $>25 \mathrm{hrs}$ & $23(54.7 \%)$ & $9(5.3 \%)$ \\
\hline \multirow{2}{*}{ Malpresentation } & Yes & $37(83.3 \%)$ & $5(3.0 \%)$ \\
\hline & No & $7(16.7 \%)$ & $163(97.0 \%)$ \\
\hline \multirow{2}{*}{ Uterotenic use } & Yes & $28(68.2 \%)$ & $23(13.7 \%)$ \\
\hline & No & $14(31.8 \%)$ & $145(86.3 \%)$ \\
\hline
\end{tabular}

\section{Factors associated with uterine rupture}

In the bivariate analysis, residence, ANC follow up, previous uterine scar, obstructed labor, gestational age, uterotenic drug use, duration of labor and gravidity were found to have significant association with uterine rupture.

After controlling confounding factors using multiple logistic regression model, rural residence, lack of ANC follow up, presence of previous uterine scar, obstructed labor, labor duration and gravidity were found to be significantly associated with the outcome variable, uterine rupture. 
Table 3: Bivariate and multiple logistic regression analysis of factors associated with uterine rupture among women visited Dessie Referral Hospitals delivery unit from January 2016 to June $2016(\mathrm{n}=210)$.

\begin{tabular}{|c|c|c|c|c|c|c|}
\hline Variable & & $\begin{array}{l}\text { Cases } \\
\mathrm{N}=42\end{array}$ & $\begin{array}{l}\text { Control } \\
N=168\end{array}$ & COR 95\% CI & AOR 95\% CI & $\begin{array}{l}\text { P- } \\
\text { Value }\end{array}$ \\
\hline \multirow{2}{*}{ Residence } & Urban & 4 & 85 & $0.12(0.34-0.31)$ & $0.12(0.02-0.75)$ & 0.023 \\
\hline & Rural & 38 & 83 & 1 & 1 & \\
\hline \multirow{2}{*}{ Previous C/s Scar } & Yes & 25 & 29 & $6.78(3.28-13.99)$ & $13.60(2.16-17.84)$ & 0.005 \\
\hline & No & 17 & 139 & 1 & 1 & \\
\hline \multirow{2}{*}{ ANC } & Yes & 10 & 132 & $0.08(0.03-0.17)$ & $0.07(0.01-0.37)$ & 0.002 \\
\hline & No & 32 & 36 & 1 & 1 & \\
\hline \multirow{2}{*}{ Obstructed labor } & Yes & 32 & 20 & $24.67(10.65-57-12)$ & $22.42(2.79-4.12)$ & 0.003 \\
\hline & No & 10 & 148 & 1 & 1 & \\
\hline \multirow{4}{*}{ Duration of labor } & $<8 \mathrm{hrs}$ & 2 & 41 & $0.21(0.12-0.23)$ & $0.14(0.01-0.21)$ & 0.002 \\
\hline & 9-14hrs & 4 & 90 & $0.11(0.34-0.78)$ & $0.17(0.01-0.56)$ & 0.012 \\
\hline & $15-24$ & 13 & 28 & $0.01(1.45-2.34)$ & $3.792(0.30-7.65)$ & 0.041 \\
\hline & $>25 \mathrm{hrs}$ & 23 & 9 & 1 & 1 & \\
\hline \multirow{4}{*}{ Gestational age } & $<37$ & 2 & 3 & $0.80(0.04-17.20)$ & $0.45(5.43-37.30)$ & 0.862 \\
\hline & $38-40$ & 32 & 150 & $3.43(0.88-13.43$ & $1.82(0.01-15.06)$ & 0.888 \\
\hline & $41-42$ & 4 & 10 & $2(0.35-11.54)$ & $0.31(4.17-24.22)$ & 0.794 \\
\hline & $>42$ & 4 & 5 & 1 & 1 & \\
\hline \multirow{3}{*}{ Gravidity } & Primi & 2 & 57 & $0.71(0.13-4.01)$ & $0.008(00-0.2)$ & 0.003 \\
\hline & Multi & 4 & 83 & $0.03(0.01-0.15)$ & $0.012(0.001-0.11)$ & 0.000 \\
\hline & Grand multi & 36 & 28 & 1 & 1 & \\
\hline \multirow{2}{*}{ Uterotenic drug use } & Yes & 28 & 23 & $3.22(1.47-7.05)$ & $5.79(0.52-64.18)$ & 0.153 \\
\hline & No & 14 & 145 & & 1 & \\
\hline
\end{tabular}

\section{DISCUSSION}

This study was aimed to explore determinants of uterine rupture among women getting delivery services in Dessie referral hospital, north east Ethiopia. The most frequently occurred risk factors of uterine rupture in this study were; rural residence $(94.2 \%)$, prolonged and obstructed labor $(54.7 \%, 76.2 \%$ respectively), malpresentation $(83.3 \%)$, grand multipara $(85.7 \%)$, lack of ANC visit (92.9\%), previous caesarian section scar $(56.8 \%)$ and uterotonic drug use $(68.2 \%)$. In addition occurrence of uterine rupture was associated with lack of ANC visit, rural residence, prolonged labor, obstructed labor, previous caesarian section scar and gravidity.

In this women who had obstructed labor $(\mathrm{AOR}=22.2$, 95\% $\mathrm{CI}=2.8-4.1)$ were at higher risk of developing uterine rupture than those women who had no obstructed labor. This result is in line with the study done in Nigeria, Niger and Ethiopia. ${ }^{17,23,24}$ The possible reasons might be, in the presence of obstructed labor not only uterus but bladder and other urinary tract organs are also more prone to be compressed by the presenting fetus for extended period. As a result uterine rupture may occur. The similarity between these studies might be due to similar socio-economic characteristics and status of health setting of the countries.
Antenatal follow-up was found to have significant association with uterine rupture in this study. Women who had ANC follow-up ( $\mathrm{AOR}=0.08$, 95\% $\mathrm{CI}=0.03$ 0.17 ) were at lower risk of encountering uterine rupture than those women who had no ANC follow up. This is in line with studies done in other developing countries. ${ }^{25-27}$ The similarity might also be due to the fact that having ANC follow-up minimizes the risk of maternal mortality and morbidity regardless of variation in living region.

There was statistically significant association between presence of previous uterine scar and uterine rupture. Those women who had previous caesarian section scar ( $\mathrm{AOR}=13.6,95 \% \mathrm{CI}=2.16-17.84)$ were more likely to have uterine rupture than that of women who had no caesarian section scar. ${ }^{26}$ This might be due to the fact that uterus with previous scar would have less elasticity and more prone to be ruptured as the fetus grows and during delivery.

The study also found strong association between uterine rupture and duration of labor. Women who had less than 8 hours duration of labor $(\mathrm{AOR}=0.14,95 \% \mathrm{CI}=0.01-0.21$, $\mathrm{P}$-value $=0.002)$ were less likely to have uterine rupture than those who had $>25$ hours duration of labor. In addition, women who had labor lasted 9-14 hours (AOR $=0.17,95 \% \mathrm{CI}=0.01-0.56)$ were less likely to have uterine rupture than women who had labor duration of $>25$ hours. This finding is consistent with study done in 
Ethiopia. The might be due to obstructed labor as it is known risk for prolonged labor and there by uterine rupture. The consistency between these studies might be explained by similarity in living and health care setting. ${ }^{26,27}$ There was a significant association between residence of respondents and uterine rupture. Those women who live in urban area $(\mathrm{AOR}=0.12,95 \%$ $\mathrm{CI}=0.02-0.75)$ were less likely to have uterine rupture than that of women who live in the rural area. This might be due; most women in the rural area have low economic status, low access to education, less aware on labor and delivery complications and low utilization of maternal health services. Number of pregnancy (gravidity) was significantly associated with uterine rupture. Those mothers who had got pregnancy once $(\mathrm{AOR}=0.008,95 \%$ $\mathrm{CI}=0.001-0.11)$ were at lower risk of having uterine rupture than that of women who have more than 5 pregnancies. This is similar with findings in studies done in Nigeria, Uganda and Ethiopia. This might be due to the fact that, as the age and number of pregnancy increases the uterus would get less elastic and this lack of elasticity may leads to uterine rupture.

\section{CONCLUSION}

This study revealed that rural residency, lack of ANC follow up, prolonged labor, obstructed labor, multiparity and history of previous caesarean section scar were risk factors for uterine rupture. Ministry of Health and Regional health bureau should establish a health care program which focuses on improving quality and coverage of maternity care by increasing investment in health system, human resources, medical equipment's and access to health for rural community.

\section{ACKNOWLEDGMENTS}

Authors are grateful to Wollo University for funding this research project. Authors would also like to thank to Dessie Referral Hospital for providing us the required data to carry out the research project. At most authors are grateful to all data collectors and study participants for their valuable contribution for realizing the research project.

Funding: No funding sources

Conflict of interest: None declared

Ethical approval: The study was approved by the Institutional Ethics Committee of College of Medicine \& Health sciences, Wollo University

\section{REFERENCES}

1. Alkema L, Chou D, Hogan D, Zhang S, Moller AB, Gemmill A, et al. Global, regional, and national levels and trends in maternal mortality between 1990 and 2015, with scenario-based projections to 2030: a systematic analysis by the UN Maternal Mortality Estimation Inter-Agency Group. Lancet. 2016;387(10017):462-74.
2. Bongaarts J, WHO, UNICEF, UNFPA, World Bank Group, and United Nations Population Division Trends in Maternal Mortality: 1990 to 2015 Geneva: World Health Organization, 2015. Population Dev Rev. 2016. 42(4):726-6.

3. Bibi S, Gul K, Gul Z, Gul P. Management of patients with uterine rupture. J Surg Pak (International). 2014;19(3):117-20.

4. Akaba GO, Onafowokan O, Offiong RA, Omonua K, Ekele BA. Uterine rupture: trends and feto-maternal outcome in a Nigerian teaching hospital. Niger $\mathbf{J}$ Med. 2013;22(4):304-8.

5. Ephraim G, Makonnen A, Seid M, Fasil T. Analysis of deliveries in Jimma Hospital, a four year retrospective study. Ethiopian J Health Dev. 1991;5(1):3-6.

6. Zwart JJ, Richters JM, Öry F, De Vries JI, Bloemenkamp KW, Van Roosmalen J. Severe maternal morbidity during pregnancy, delivery and puerperium in the Netherlands: a nationwide population-based study of 371000 pregnancies. BJOG. 2008;115(7):842-50.

7. Astatikie G, Limenih MA, Kebede M. Maternal and fetal outcomes of uterine rupture and factors associated with maternal death secondary to uterine rupture. BMC Pregnancy childbirth. 2017 Dec;17(1):117.

8. Kramer MS, Berg C, Abenhaim H, Dahhou M, Rouleau J, Mehrabadi A et al. Incidence, risk factors, and temporal trends in severe postpartum hemorrhage. Am J Obstet Gynecol. 2013 Nov 1;209(5):449-e1.

9. Loue VA, Dia JM, Effoh DN, Adjoby RC, Konan JK, Gbary EAet al. Management and prognosis of uterine rupture during labor in an under-medicalized country: about 513 cases collected at the Cocody University Hospital Center (Abidjan-Cote d'Ivoire). Int J Reprod Contracept Obstet Gynecol. 2017;4(5):1277-82.

10. Bashir A, Ashraf R, Shakoor S, Ali F, Rehman K, Chohan A. Uterine Rupture: an audit to analyze management options, maternal \& fetal outcome. Annals King Edward Medical University. 2016 Apr 7;11(1).

11. Motomura K, Ganchimeg T, Nagata C, Ota E, Vogel JP, Betran AP et al. Incidence and outcomes of uterine rupture among women with prior caesarean section: WHO Multicountry Survey on Maternal and Newborn Health. Scientific reports. 2017 Mar 10;7:44093.

12. Sunitha K, Indira I, Suguna P. Clinical study of rupture uterus-Assessment of Maternal and fetal outcome. J Dental Med Sci. 2015;14(3):39-45.

13. Rizwan N, Abbasi RM, Uddin SF. Uddin, Uterine rupture, frequency of cases and fetomaternal outcome. JPMA. 2011;61(4):322.

14. Saeed S, Ahmad A, Akhtar N. Uterine rupture; four years experience on seventy four cases in secondary Care Hospital. Professional Med J. 2015;22(8). 
15. Desai RS, Kamat AV. Rupture uterus: a prospective observational study of 25 consecutive cases in a tertiary referral centre in South India. Int J Reprod Contracept Obstet Gynecol. 2017 May 25;6(6):26016.

16. Jain R. Rupture of pregnant uterus: incidence, risk factors, maternal and fetal outcome. Int J Med Res Rev. 2016;4(06).

17. Aboyeji AP, Ijaiya MD, Yahaya UR. Ruptured uterus: a study of 100 consecutive cases in Ilorin, Nigeria. J Obstet Gynaecol Res. 2001 Dec $1 ; 27(6): 341-8$.

18. Kaczmarczyk M, Sparén P, Terry P, Cnattingius S. Risk factors for uterine rupture and neonatal consequences of uterine rupture: a population-based study of successive pregnancies in Sweden. BJOG: Int J Obstet Gynaecol. 2007 Oct 1;114(10):1208-14.

19. Kabore C, Chaillet N, Kouanda S, Bujold E, Traore M, Dumont A. Maternal and perinatal outcomes associated with a trial of labour after previous caesarean section in sub-Saharan countries. BJOG: Int J Obstet Gynaecol. 2016 Dec 1;123(13):2147-55.

20. Khooharo Y, Yousfani JZ, Malik SH, Amber A, Majeed $\mathrm{N}$ et al. Incidence and management of rupture uterus in obstructed labour. J Ayub Med Coll Abbottabad. 2013 Jun 1;25(1-2):149-51.

21. Gessessew A, Melese MM. Ruptured uterus-eight year retrospective analysis of causes and management outcome in Adigrat Hospital, Tigray Region, Ethiopia. Ethiopian J Health Development. 2002;16(3):241-5.

22. Berhe Y, Gidey H, Wall LL. Uterine rupture in Mekelle, northern Ethiopia, between 2009 and 2013.
International Journal of Gynecol Obstet. 2015 Aug 1;130(2):153-6.

23. Gebre S, Negassi A. Risk factors for uterine rupture in Suhul General Hospital case control study. Electronic J Biol. 2017 Jul 1;13(3).

24. Spong CY, Landon MB, Gilbert S, Rouse DJ, Leveno KJ, Varner MW et al. Risk of uterine rupture and adverse perinatal outcome at term after cesarean delivery. Obstet Gynecol. 2007 Oct 1;110(4):801-7.

25. Aliyu LD, Elnafaty AU, Kadas SA, Dattijo LM, Aminu BM. Uterine rupture an obstetrics catastrophy; incidence, risk factors, management and outcome at Abubakar Tafawa Balewa University Teaching Hospital Bauchi Nigeria. Trop J Obstet Gynaecol. 2012;29(1):13-7.

26. Mukasa PK, Kabakyenga J, Senkungu JK, Ngonzi J, Kyalimpa M, Roosmalen VJ. Uterine rupture in a teaching hospital in Mbarara, western Uganda, unmatched case-control study. Reproductive Health. 2013 Dec;10(1):29.

27. Justus Hofmeyr G, Say L, Metin Gülmezoglu A. Systematic review: WHO systematic review of maternal mortality and morbidity: the prevalence of uterine rupture. BJOG: An Int J Obstet Gynaecol. 2005 Sep 1;112(9):1221-8.

Cite this article as: Workie A, Getachew Y, Temesgen K, Kumar P. Determinants of uterine rupture in Dessie Referral Hospital, North East Ethiopia, 2016: case control design. Int J Reprod Contracept Obstet Gynecol 2018;7:1712-7. 